\title{
EFFECT OF STRENGTH ON COTTON AND BLENDED Mattress Fabric Produced by Mechanical Processing SYSTEM
}

\author{
Md. Abul Kalam Azad ${ }^{1}$, Shamina Jafrin ${ }^{1}$, and Md. Tahzibul Haque (Shahin) ${ }^{2}$ \\ ${ }^{1}$ Bangladesh Jute Research Institute, Dhaka, Bangladesh. and \\ ${ }^{2}$ Khulna University of Engineering \& Technology (KUET) \\ E-mail : sjafrin@ gmail.com
}

\begin{abstract}
Mattress fabric is one time used fabric. It need not require for washing. In this perspective, a project was taken to replace $100 \%$ cotton mattress fabric instead of Jute-Cotton blended mattress fabric. It is seen that Jute: Cotton blended mattress fabric posses similar properties to the $100 \%$ cotton mattress fabric. Bursting strength is an important factor for mattress fabric. From the comparison result, it is also seen that the bursting strength of 80:20/Jute: Cotton blended mattress fabric is nearer to the $100 \%$ cotton mattress fabric. On the other hand, blended mattress fabric is cheaper than $100 \%$ Cotton mattress fabric. Hence, blended mattress fabric may be the replacement of $100 \%$ cotton mattress fabric.
\end{abstract}

Keywords: Strength, Mattress, Jute-cotton Union, Mechanical, Warpwise, Waftwise, Bursting.

\section{Introduction}

Jute, the golden fibre of Bangladesh has got various inherent characteristics like high tensile strength, low extensibility, long durability, luster and long staple length. It is a textile fibre of good spinnable character [1]. It forms nontraditional and value-added products helping in environment protection and maintaining ecological balance.

$100 \%$ Cotton is also a natural seed fibre. It is imported form different countries like Egypt, USA, China, and South Africa etc. for making garments. Percentage of cellulose present in Cotton (94\%) which is higher than jute (64\%). So it is also called cellulosic fibre. That is why price of cotton is higher than jute. Jute is the cheapest natural fibre used for the manufacture of different goods which are highly in demand both in the domestic as well as foreign markets [2]. Jute-Cotton blended mattress cover fabric are cost-effective than the $100 \%$ cotton mattress fabric. The newly evolved jute based blended yarns will be a better raw materials for value added diversified products. Mattress is one kind of diversified product.

Mattress means a bed made of stuffed bag. Generally mattress are prepared by the $100 \%$ cotton fabric mattress fabric is a house hold useable fabric. Mattress fabric does not need wash as apparels do. It has to be the power to with stand the load. So bursting strength is an important factor for mattress fabric [3].

As these blended and $100 \%$ cotton jute fabrics are environment friendly, biodegradable cheap and can be manufactured on hand as well as on power looms, so a new outlet would be created as on power looms [4,5].

So, in on.e side the diversification of jute products will be increased and the other side low cost mattress will be produce.

\section{Materials and Methods}

2.1. Fabrics: $100 \%$ cotton fabrics, jute-cotton union fabric.

\subsection{Collection of jute and cotton fibre}

Jute fibre and $100 \%$ cotton fabrics were collected from the local market. Cost of the $100 \%$ cotton is Tk.30/ metre

\subsection{Experimental procedure}

For producing Jute: Cotton blended yarn, the jute fibres (which were collected from the local market) were cut in to pieces of two inch in length by the cutting machine. Then the cutted jute fibres were chemically modified i.e white and softening by the chemicals. The chemically treated jute fibres were dried by the drying machine. After drying the fibres were separated/opened with the opening machine. After proper opening, the chemically modified fibres were blended with cotton at the ratio of 
80:20/Jute: Cotton in the blow room section. A fully modern blow room with eight blending chamber is used for uniform blending of Jute and Cotton.

Then the blended lap of blowroom is passed into the carding machine to get the suitable sliver. After that, the belnded sliver is passed in to the drawing frame to get the uniform sliver. Finally, Jute-Cotton blended yarn was prepared with the rotor (Open end) machine from Al-Rajee spinning Mill ltd. Katchpur, Narayangonj, Dhaka, 80:20 jute: cotton blended yarns were produced for blended mattress.

Fabric was prepared in the normal power loom of Jute and Textile Produced Development Centre (JTPDC). Then the blended mattress fabric and $100 \%$ cotton mattress fabric were tested in the testing department of Bangladesh Jute Research Institute (BJRI). The test results are shown in the table. The physical properties of the mattress fabric through various treatments were tested in the Testing Department of Bangladesh Jute Research Institute (BJRI). The bending length tensile strength and abrasion resistance of the fabric was determined by Shirley Stiffness Tester, Tensile Strength Tester and Abrasion Tester [6].

\section{Result}

All the tests were performed in the standard testing atmosphere and the results are shown in the table.

\begin{tabular}{|c|c|c|c|}
\hline \multirow{2}{*}{$\begin{array}{l}\text { Sl. } \\
\text { No. } \\
1 .\end{array}$} & $\begin{array}{c}\text { Fabri } \\
\text { c }\end{array}$ & \multicolumn{2}{|c|}{ Observation } \\
\hline & \multirow{10}{*}{$\begin{array}{l}100 \% \\
\text { Cotto } \\
n\end{array}$} & Warp count & $10 \mathrm{~s}$ \\
\hline & & Weft count & $10 \mathrm{~s}$ \\
\hline & & End/Inch & 38 \\
\hline & & Pick/Inch & 26 \\
\hline & & $\mathrm{Wt} / \mathrm{Sq} \cdot \mathrm{m}(\mathrm{gm})$ & 335.5 \\
\hline & & $\begin{array}{l}\text { Warp wise strength } \\
\text { (Kgf) }\end{array}$ & 140.1 \\
\hline & & $\begin{array}{l}\text { Weft wise strength } \\
\text { (Kgf) }\end{array}$ & 130.3 \\
\hline & & $\begin{array}{l}\text { Blending length } \\
(\mathrm{cm} .)\end{array}$ & 3.0 \\
\hline & & Abrasion resistance & $\begin{array}{l}\text { Very } \\
\text { excellent }\end{array}$ \\
\hline & & $\begin{array}{l}\text { Bursting strength } \\
\text { (Ibsq. inch }^{-1} \text { ) }\end{array}$ & 149.8 \\
\hline 2. & Jute- & Warp count & $10^{5}$ \\
\hline
\end{tabular}

\begin{tabular}{|c|c|c|}
\hline \multirow{9}{*}{$\begin{array}{l}\text { Cotto } \\
\mathrm{n} \\
\text { blend } \\
\text { ed } \\
\text { fabric } \\
(80: 2 \\
0)\end{array}$} & Weft count & $12^{1}$ \\
\hline & End/Inch & 36 \\
\hline & Pick/Inch & 18 \\
\hline & Wt/ Sq.m(gm) & 342 \\
\hline & $\begin{array}{l}\text { Warp wise strength } \\
\text { (Kgf) }\end{array}$ & 138 \\
\hline & $\begin{array}{l}\text { Weft wise strength } \\
\text { (Kgf) }\end{array}$ & 128.5 \\
\hline & $\begin{array}{l}\text { Bending length } \\
(\mathrm{cm} .)\end{array}$ & 3.2 \\
\hline & Abrasio resistance & $\begin{array}{l}\text { Very } \\
\text { excellent }\end{array}$ \\
\hline & $\begin{array}{l}\text { Bursting strength ( } \\
\text { Ibsq. inch }^{-1} \text { ) }\end{array}$ & 148.5 \\
\hline
\end{tabular}

The relation between the warp, weft \& Bursting strength of blended and $100 \%$ Cotton mattress fabric is shown in the Fig 1.

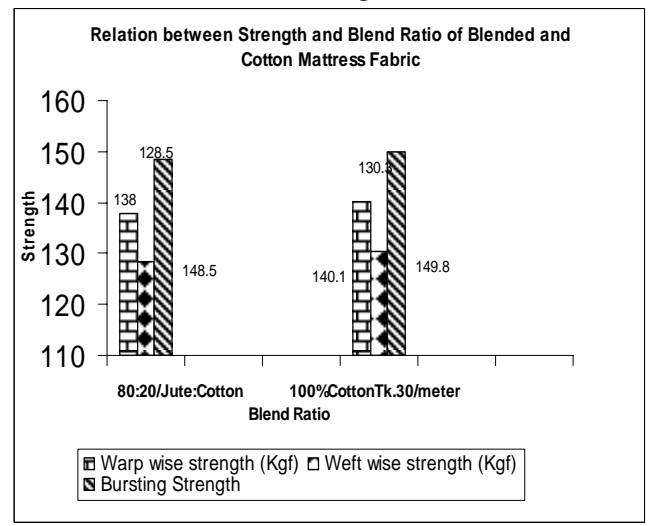

Fig: 1

\section{Discussion}

In Fig. 1, the horizontal line and the vertical line indicates the blend ratio and strength respectively. For 80:20/jute: cotton blended mattress fabric the warp-wise and weft-wise strength were $36 \mathrm{kgf}$ and $25.19 \mathrm{kgf}$. For 100\% cotton fabric (Tk.30 meter) the warp-wise and weft-wise strength were $40 \mathrm{kgf}$ and $28 \mathrm{kgf}$ respectively. Two types of yarn are essential for producing the fabric. One is longitudinal and another is transverse yarn. The longitudinal yarn is called warp yarn and the transverse yarn is called the weft yarn. For mattress cover, the strength of the fabric is an important factor. The strength also depend on the thickness i.e wt/sq.m (gm) of the fabric of same type of yarn $[7,8]$.

From the above results, it is seen that the strength of $100 \%$ Cotton yarn is higher than the strength of 80:20/jute cotton blended yarn. From the figure1, it was observed that the wt. of 80:20 jute:cotton blended mattress cover 
fabric is higher than that the wt. of $100 \%$ Cotton fabric (Tk. $30 \mathrm{~m}^{-1}$ ) .

80:20/jute: cotton mattress fabric is also comparable and acceptable for the running items in the Market. As cotton fibre is stronger than jute fibre that is why $100 \%$ cotton mattress fabric has shown higher strength than 80:20 /Jute: Cotton mattress cover fabric.

The bursting strength of the $100 \%$ cotton fabric (Tk. $30 \mathrm{~m}^{-1}$ ) was 149.8 Ibsq. inch ${ }^{-1}$. But the bursting strength of 80:20/jute: Cotton mattress fabric was very nearer to the bursting strength of $100 \%$ cotton mattress fabric. Bursting strength is a force which is used in a certain length to burst the fabric. It is a very important property of mattress cover. This property has no limit or standard. Higher the bursting strength indicates the good quality of the mattress fabric [9].

The strength of blended mattress fabric was compared to the $100 \%$ cotton mattress fabric. When the portion of jute had increased in the blend, the wt. of the matters fabric also increased simultaneously. As the wt. had increased due to thickness of the fabric, the bursting strength had also increased for 80:20/jute: cotton: blended mattress fabric. The 80:20/jute: cotton blended mattress fabric and $100 \%$ cotton mattress fabric (Tk. $30 \mathrm{~m}^{-1}$ ) showed very nearer bursting strength.

\section{Conclusion}

Strength is an important issue for mattress fabric than the other properties of the fabric. Hence, warp wise, weft -wise and specially bursting strength plays the vital role for the longevity of the mattress fabric. Here, the bursting strength of 80:20/Jute:Cotton blended mattress fabrics is very similar to the low price
$100 \%$ cotton mattress fabric (i.e tk $30 \mathrm{~m}^{-1}$ ). So, undoubtedly 80:20/Jute: Cotton blended mattress fabric may be the best replacement of $100 \%$ low quality mattress fabric and this will help to increase the use of jute based diversified products.

\section{References}

[1] Mahabubuzzaman A.K.M., Miazi M. O. Ghani, Uddin M. K., Lutfar Latifa Binte and Jubayer Minhajj Uddin. "Effect of Spindle Speed On Twist and Strength Of All Jute Yarn In Modified Apron Draft Ring Spinning Frame”. Bangladesh Journal of Jute and Fibre Research .Vol. 26 (1-2). 2006. .pp-39-44.

[2] Engr. Azad Md. Abul Kalam Engr. Chwodury Nazmina Nazmina, Engr. Abdus Salam Khan and Uddin M.K. "Studies on the development of the bags in the cottage industry ." South East.

[3] Md. Abul Kalam Azad, "Influence of blender ratio on the properties of rotor spun yarns" Jahangir Nagar University, Savar, Dhaka,P.hd. February.2007.

[4] Booth JE. Principles of textile testing” 1996. PP.433. Publilshed by- S.K.Join, 4596/1 A, testing Darya Ganij, New Delhi-1100002 (India)

[5] Langenhov V. Note for practical weaving Head textile deptt. Gent. Uni Bel. P : 91.1995.

[6] Textile Research Journal, 1991, pp-21

[7] Chu. C.C Cumneing C.L and Textiiea N.A, Physical properties of cotton uphostery. J. Text. Res.20:39:1960.

[8] Vanghaluwe, L. Mechanism of weaving. Head of Textile Department, Gent. University, Gelgium. 86-94, 1995.

[9] Sudnik, Z. M, Practical opproacch of quality testing of Upholstrey fabrics J.test. Inst. 52: 442. 1961. 